\title{
Comparison of the Effectiveness of Cognitive-Behavioral Therapy and Neurofeedback for Reducing Symptoms of Anxiety
}

\author{
Zahra Shokhmgar ${ }^{1}$, Akram Sanagoo ${ }^{2}$, Malieh Mohammadpour ${ }^{3}$, Hosein Khaleghi $^{4}$, Akram Ahangi ${ }^{5}$, \\ Neda Mehrandish ${ }^{6}$, Leila Mirshekari*7
}

1. Department of Psychology, Payame Noor University, Torbat-e Jam, Iran

2. Nursing Research Center, Golestan University of Medical Sciences, Gorgan, Iran

3. Department of Sociology, Payame Noor University, Torbat-e Jam, Iran

4. Department of Management, Payame Noor University, Torbat-e Jam, Iran

5. Department of Psychology, Payame Noor University, Tehran, Iran

6. Allameh Tabataba'i University, Tehran, Iran

7. Iran University of Medical Sciences, Tehran, Iran

\begin{abstract}
Background and objectives: Anxiety is one of the most common psychiatric disorders that can cause functional impairment, which necessitates development of novel diagnostic and therapeutic methods. The aim of this study was to compare the effectiveness of cognitive-behavioral therapy and neurofeedback in reducing symptoms of anxiety.

Methods: This was a quasi-experimental study with a pretest-posttest design. Study population included 24 students with anxiety disorders who were referred to the psychological consultation center at Payame Noor University, Torbat-e Jam (Iran) in 2018. The subjects were selected based on psychiatric interview and the DSM-5 diagnostic criteria. They were randomly divided into two groups: the first group received 10 weekly 90-minute sessions of cognitive-behavioral group therapy, while the second group received 10 weekly 30-minute sessions of neurofeedback. Data were analyzed using SPSS software (version 20) at significance level of 0.05.

Results: The groups were matched in terms of age and education level. The mean pretest score of anxiety did not differ significantly between the groups $(\mathrm{P}=0.01)$. After the intervention, the mean score of anxiety decreased significantly in the cognitive-behavioral therapy group $(\mathrm{P}=0.001)$ and in the neurofeedback group $(\mathrm{P}=0.0001)$. There was a significant difference between the effects of neurofeedback and cognitive-behavioral group therapy $(\mathrm{P}=0.012)$.

Conclusion: Our results suggest that both cognitive-behavioral therapy and neurofeedback can significantly reduce symptoms of anxiety in students. However, the effectiveness of neurofeedback is significantly higher than that of cognitive-behavioral therapy in reducing the symptoms of anxiety.
\end{abstract}

Keywords: Anxiety disorder, cognitive-behavioral therapy, neurofeedback

\section{$\begin{array}{lll}\text { Received: 2019/03/31 } & \text { Revised: 2019/04/20 } & \text { Published: 2019/07/31 }\end{array}$}

*Correspondence: Leila Mirshekari, Iran University of Medical Sciences, Tehran, Iran

Tel: +98-9054428720

Email: mirshekari2000@gmail.com

This article is distributed under the terms of the Creative Commons Attribution 4.0 International License (http://creativecommons.org/licenses/by/4.0/), which permits non-commercial use of it while providing appropriate credit to the original author(s) and the source. 


\section{INTRODUCTION}

Anxiety is a common mental health disorder that negatively affects physical health, performance and adaptability, ultimately reducing quality of life (1). It is believed that thinking styles can make individuals vulnerable to anxiety disorders (2). In recent decades, several methods have been used to reduce anxiety, such as cognitive-behavioral techniques, relaxation, regular sensitization, stress immunization and cognitive therapy based on the models presented by Beck or Ellis (3). Anxiety can be treated by medication and cognitive-behavioral therapies. Meditation, yoga, relaxation, biofeedback and neurofeedback are among the treatments applied to cope with anxiety and stress (4).

Cognitive-behavioral therapy is a combination of cognitive and behavioral approaches that help one identify and address distorted thinking and ineffective behaviors patterns through regular discussions and organized behavior assignments (5). This type of therapy is effective in creating and enhancing capabilities such as decision making, motivation, acceptance of responsibility, positive relationship with others, happiness, self-esteem, problem solving, self-regulation, self-efficacy and mental health (6). A study has proposed cognitive-behavioral therapy as an effective empirical approach for treatment of anxiety disorders (7). In another study, although cognitive-behavioral therapy and muscle relaxation were effective for reducing symptoms in adults with generalized anxiety disorder, the effectiveness of cognitivebehavioral therapy was higher than muscle relaxation (8).

Neurofeedback is based on electrical brain activity (9) and helps one reach his/her optimal performance level (10). The neurofeedback process involves selfregulation training or self-regulation of brain activity. The brain controls blood flow to regions that contribute to self-regulation by vasodilation and vasoconstriction (11). The goal of neurofeedback is to normalize abnormal electroencephalography (EEG) frequencies by raising awareness on normalized EEG patterns (12). Neurofeedback can be used to treat a wide range of psychological conditions including aggression, anger, depression, anxiety, mood disorders, attention deficit hyperactivity disorder, etc. (13-27).

Given the lack of enough research on the effects of neurofeedback on psychiatric disorders in the Iranian population, drugs side effects, and the low rate of recovery in some patients, we aimed to compare effectiveness of neurofeedback and cognitive-behavioral therapy for improving anxiety symptoms in students with anxiety disorders.

\section{MATERIAL AND METHODS}

Study design and population

This was a quasi-experimental study with a pretest-posttest design. The study was performed on 24 students with anxiety disorders who were referred to the psychological consultation center at Payame Noor University, Torbat-e Jam (Iran) in 2018. The subjects were selected based on psychiatric interview and the DSM-5 diagnostic criteria. They were enrolled via availability sampling and then were randomly divided into two groups: neurofeedback and cognitive-behavioral therapy. The first group received 10 weekly sessions (90 minutes a session) of cognitive-behavioral group therapy, while the second group received 10 weekly sessions (30 minutes a session) of neurofeedback. The subjects completed the Cattell Anxiety Scale (28) before and after the intervention. Inclusion criteria included having anxiety and age of 20-30 years. Exclusion criteria were participation in a previous treatment program and a history of mental illness, hospitalization in psychiatric wards, and drug or alcohol consumption.

\section{Research instruments}

The Cattell Anxiety Scale

The scale consists of 40 items (20 items on hidden anxiety and 20 on apparent anxiety) 
that are rated on a 3-point scale with a cut-off score of 30. The Cronbach's alpha reliability coefficient value was 0.91 for hidden anxiety and 0.93 for the apparent anxiety subscales. The retest reliability for the hidden anxiety and apparent anxiety subscales was 0.86 and 0.63 , respectively. In this study, the Cronbach's alpha reliability coefficient value was 0.89 for the hidden anxiety and 0.91 for the apparent anxiety subscales (28).

\section{Neurofeedback equipment}

In this study, this training method was considered as an independent variable. The neurofeedback training was conducted using devices equipped with computer systems and under a researcher's supervision in form of 10 weekly sessions (30 minutes a session).

\section{Treatment plan}

Session instructions were based on the Michael Frey's method of cognitivebehavioral group therapy (29).

\section{Ethical considerations}

Before enrollment, the subjects were briefed about the research objectives and how to respond to the questionnaires, and were assured of the confidentiality of their information. The subjects could freely withdraw from the study at any point if they were unwilling to continue participating in the study.

\section{Data analysis}

Data were analyzed with SPSS software (version 20) using descriptive statistics, analysis of variance and t-test at significance level of 0.05 .

\section{RESULTS}

At baseline, the mean score of anxiety was 45.5 in the neurofeedback group and 32.5 in the cognitive-behavioral therapy group (Table 1). After the intervention, the mean score anxiety decreased significantly in the cognitive-behavioral therapy group $(\mathrm{P}=0.001)$ and in the neurofeedback group $\quad(\mathrm{P}=0.0001)$.

Table 1. Comparison of the effectiveness of neurofeedback and cognitive-behavioral therapy on anxiety symptoms based on dependent t-test

\begin{tabular}{|c|c|c|c|c|c|}
\hline Group & Significance level & $\begin{array}{c}\text { Degrees of } \\
\text { freedom }\end{array}$ & $\mathbf{t}$ & $\begin{array}{c}\text { Mean pretest } \\
\text { score of anxiety }\end{array}$ & $\begin{array}{c}\text { Mean posttest } \\
\text { score of anxiety }\end{array}$ \\
\hline Neurofeedback & 0.0001 & 11 & 7.82 & 45.5 & 9.5 \\
\hline $\begin{array}{c}\text { Cognitive-behavioral } \\
\text { therapy }\end{array}$ & 0.001 & 11 & 4.24 & 32.5 & 13.4 \\
\hline
\end{tabular}

*P-value $<0.01$

Cohen's $d$ value was less than 0.2 in the cognitive-behavioral therapy group and 4.23 in the neurofeedback group, which suggests that neurofeedback was significantly more effective than cognitive-behavioral therapy in reducing symptoms of anxiety $(\mathrm{P}=0.012)$.

\section{DISCUSSION}

The results of this study showed that both cognitive-behavioral therapy and neurofeedback can significantly reduce anxiety. However, the effect of neurofeedback was more noteworthy than that of cognitivebehavioral therapy.

Previous studies have recommended both of these therapies, but neurofeedback is a relatively newer approach to the treatment of anxiety disorders. Neurofeedback is effective for the treatment of psychiatric disorders such as attention deficit hyperactivity disorder, general anxiety disorder, obsessivecompulsive disorder, post-traumatic stress disorder, depression, dissociative disorders, 
learning difficulties, schizophrenia and drug dependence. Efficacy of combinational therapy with neurofeedback and cognitivebehavioral therapy has also been investigated for treatment of the aforementioned conditions (25). Numerous studies have demonstrated that neurofeedback is effective for treatment of anxiety (30-40). Neurofeedback helps individuals through conditioning in order to promote psychosocial responses and anxiety control. It can also reduce anxiety and mood disorders by conditioning brain waves. In this way, anxiety can be reduced by focusing on the animation presented in certain circumstances and extend the duration of relaxation by repeating the sessions. In protocols that are effective in reducing anxiety, people usually feel relaxed after about five minutes. Subject becomes familiar with the physiological and neurological changes by practice through repetition, which can intensify the relaxation effect of the therapy in a safe and painless manner (16). The anxious person is consciously and voluntarily learning how to reduce his anxiety without medication. Neurofeedback can help a person develop certain skills that are necessary for the safe and effective control of his/her psychological state and coping with anxious thoughts through everyday life (41).

Given the high prevalence of anxiety disorders, especially in young people, and the insufficient response to commonly used medications in a vast majority of patients, it is essential to seek novel therapeutic methods with few side effects (42). It has been reported that brain stimulation therapies such as neurofeedback and repetitive transcranial magnetic stimulation are effective for reducing symptoms in patients with anxiety disorders (43).

This was not a case-controlled study and we did not investigate some demographic variables such as the socioeconomic status, which could be limitations of this research. Conducting similar studies with a larger study population can increase the possibility of generalizing the findings.

\section{CONCLUSION}

Our results showed that both cognitivebehavioral therapy and neurofeedback have a significant positive impact on symptoms of anxiety. However, the effectiveness of neurofeedback is significantly higher than that of cognitive-behavioral therapy in reducing the symptoms of anxiety.

\section{ACKNOWLEDGMENTS}

We would like to extend our sincere gratitude to all subjects who participated in the study.

\section{DECLARATIONS \\ Funding}

Not applicable.

\section{Ethics approvals and consent to participate}

Written informed consent was obtained from all participants.

\section{Conflict of interest}

The authors declare that there is no conflict of interest regarding the publication of this article.

\section{REFERENCES}

1. Ryan, C.E., Epstein ,N.B., Keitner, G.I.,Miller,I.,\& Bishop, D. S. Evaluating and treating families : The Mc Master approach . New York: Routledge Taylor \& Francis Group,2005.

2. Morrison EW, Milliken FJ. Organizational silence: A barrier to change and development in a pluralistic world. Academy Manage Rev, 2000; 25(4): 706-25. [DOI:10.5465/amr.2000.3707697]

3. Zalipour M. The effect of systematic motivational counseling on reduce of exam anxiety among student, [MS Thesis in Persian]. Iran, Tehran: AllameTatabatabei University; 2005.

4. Najafian J, Akhavan TA .Comparison of the effect of relaxation and biofeedback- assisted relaxation on stress and anxiety score in patient with mild hypertention. Journal of Jahrom University of Medical Sciences 2011; 9(17): 8-12. [In Persian] 
5. Allison JO,Roger C, Pamela MS.David JA. A meta- analysis of CBT for Pathological worry amony clients with GAD. J Anx Disord 2016;22:108-160.

[DOI:10.1016/j.janxdis.2007.01.002]

6. Hall J, Kellett S, Berrios R, Bains MK, Scott S. Efficacy of cognitive behavioral therapy for generalized anxiety disorder in older adults: systematic review, meta-analysis, and metaregression. Am J Geria Psychiat 2016; 24(11): 1063-73. [DOI:10.1016/j.jagp.2016.06.006]

7. Olatunji B, Cisler J, Deacon B. Efficacy of cognitive behavioral therapy for anxiety disorders, Psychiatric Clin North Am 2010; 33(3): 557-57. [DOI:10.1016/j.psc.2010.04.002]

8. Dugas M, Brillon P, Savard P, Turcotte J, Gaudent A, Ladoucrar R, et al. A randomized clinical trial of cognitive-behavioral therapy and applied relaxation for adults with generalized anxiety disorder. J Behavioral 2010; 41(1): 46-58. [DOI:10.1016/j.beth.2008.12.004]

9. Lubar JF. Neurofeedback for the management of attention deficit disorders. In: Schwarts MS, Andrasik F, editors. Biofeedback: A practitioners guide. 3rd ed. New York: The Guilford Press; 2003: 409-37

10. Kouijzer MEJ, van Schie HT, de Moor JMH, Gerrits BJL, Buitelaar JK. Neurofeedback treatment in autism. Preliminary findings in behavioral, cognitive, and neurophysiological functioning. Journal of Research in Autism Spectrum Disorders 2009; 4: 386-99. [DOI:10.1016/j.rasd.2009.10.007]

11. Mann C, Lubar JF, Zimmerman A, Miller C, Muenchen R. Quantitative analysis of EEG in boys with attentiondeficit/ hyperactivity disorder: a controlled study with clinical implication. Journal of Pediatric Neurology 1992; 8(1): 30-6. [DOI:10.1016/0887-8994(92)90049-5]

12. Vernon D, Egner T, Cooper N, Compton T, Neilands C, Sheri A, et al. The effect of training distinct neurofeedback protocols on aspects of cognitive performance. Int J Psychophysiol 2003; 47(1): $\quad 75-85 . \quad$ [DOI: $10.1016 /$ S01678760(02)00091-0]
13. Bazanova OM, Aftanas LI. Individual EEG alpha activity analysis for enhancement neurofeedback efficiency: two case studies. Journal of Neurotherapy 2010; 14(3): 244-53. [DOI:10.1080/10874208.2010.501517]

14. Hammond DC. Lens neurofeedback treatment of anger: Preliminary reports. Journal of Neurotherapy $2010 ; \quad 14(2)$ : 162-9. [DOI:10.1080/10874201003767213]

15. Hammond DC. What is neurofeedback? Journal of Neurotherapy 2011; 15(4): 305-36. [DOI:10.1080/10874208.2011.623090]

16. Hammond DC. Neurofeedback treatment of depression with the roshi. Journal of Neurotherapy. 2000; 4(2): 45-56. [DOI:10.1300/J184v04n02_06]

17. Hammond DC. Neurofeedback with anxiety and affective disorders. Child AdolescPsychiatrClin N Am. 2005; 14(1): 105-23. [DOI:10.1016/j.chc.2004.07.008]

18. Bolea AS. Neurofeedback treatment of chronic inpatient schizophrenia. Journal of Neurotherapy. 2010; 14(1): 47-54. [DOI:10.1080/10874200903543971]

19. Smith PN, Marvin WS. Neurofeedback with juvenile offenders: A pilot study in the use of QEEG-based and analog-based remedial neurofeedback training. Journal of Neurotherapy.2006; $\quad 9(3): \quad$ 87-99. [DOI:10.1300/J184v09n03_06]

20. Sime A. Case study of trigeminal neuralgia using neurofeedback and peripheral biofeedback. Journal of Neurotherapy. 2004; 8(1): 59-71. [DOI:10.1300/J184v08n01_05]

21. Bakhshayesh AR, Ha"nsch S, Wyschkon A, Rezai MJ, Esser G. Neurofeedback in ADHD: A single-blind randomized controlled trial. Eur Child Adolesc Psychiatry. 2011; 20(9): 481-91. [DOI:10.1007/s00787-011-0208-y]

22. Monastra VJ, Lynn S, Linden M, Lubar JF, Gruzelier J, LaVaque TJ. Electroencephalographic biofeedback in the treatment of attentiondeficit/hyperactivity disorder. ApplPsychophysiol Biofeedback. 2005; 30(2): 95-114. [DOI:10.1007/s10484-005-4305-x] 
23. Coben R, Padolsky I. Assessment-guided neurofeedback for autistic spectrum disorder.

Journal of Neurotherapy. 2007: 11(1); 5-22. [DOI:10.1300/J184v11n01_02]

24. Coben R, Linden M, Myers TE. Neurofeedback for autistic spectrum disorder: A review of the literature. ApplPsychophysiol Biofeedback. 2011: 35(1); 83-105. [DOI:10.1007/s10484-009-9117-y]

25. Wang M, Reid D. Virtual reality in pediatric neurorehabilitation: attention deficit hyperactivity disorder, autism and cerebral palsy. Neuroepidemiology. 2010; 36(1): 2-18. [DOI:10.1159/000320847]

26. Bachers A. Neurofeedback with cerebral palsy and mental retardation: A case report. Journal of Neurotherapy.2004; $\quad 8(2)$ : $95-6$. [DOI:10.1300/J184v08n02_08]

27. Margaret EA. Neurofeedback for cerebral palsy. Journal of Neurotherapy. 2004; 8(2): 93-4. [DOI:10.1300/J184v08n02_07]

28. Hemmati, Samira (2007). The study of anxiety caused by noise pollution in factories, $\mathrm{PhD}$ dissertation of Islamic Azad University, Tehran South Branch.

29. Wilson GT, Zandberg LJ. Cognitivebehavioral guided self-help for eating disorders: effectiveness and scalability.Clin Psychol Rev. 2012; 32:343-57.

[DOI:10.1016/j.cpr.2012.03.001]

30. Jennifer, Y. (2015). Social anxiety disorder in adolescence: How developmental cognitive neuroscience findings may shape understanding and interventions for psychopathology.London. Journal of Developmental Cognitive Neuroscience. 13. 11-20.

31. Coben., R. Padalsky, I. (2002). Assessmentguided neurofeedback for autistic disorder. Clinical psychology science \& practice. 11(3), 230-24.

32. Moradi,. A. Pouladi,. F. pishva,N.Rezaei,B. Torshabi, M. Alammehrjerdi. Z.(2011). Treatment of anxiety disorder with neurofeedback. Tehran.
Procedia-social and behavioral sciences: 103-107. [DOI:10.1016/j.sbspro.2011.10.021]

33. Frank, S B. Ralf, V. Petra, S. Simon, B. Jörn, D. Rainer, GI. Klaus, M. Niels,B. k. Nikolaus, W. (2015). Manipulating motor performance and memory through real-time fMRI neurofeedback. University College London. Journal home page Biological Psychology. $108 . \quad 85-97$. [DOI:10.1016/j.biopsycho.2015.03.009]

34. Christopher, R. Andrew, C. Maria David, M. Rich. M. (2015). Investigating the efficacy of neuro feedback training for expediting expertise and excellence in sport. Psychology of Sport and Exercise $16.118 \mathrm{e} 127$ [DOI:10.1016/j.psychsport.2014.08.005]

35. Gruzelier J, G. Thompson, T. Redding, E. Brandy, R. Steffert. T. (2013).Department of psychology .university of landon.international. Journal of psychophysiology. Intpsy-10653. 17011724.

36. Biriukova, E. V. Timofeer, L.V.Mosolov, S. N. (2003). Clinical and entropy physiological efficacy of neurofeedback. Moscow. iteration an journal of nursing sciences. 9(2): 111-4.

37. Moradi A, Kalantari M. The effect of self image guided on anxiety and hope to life in women with cancer. Journal of knowledge and research in Applied Psychology. 2007; 9(31); 116. [In Persian]

38. Heidari AR, Saedi S. The effect of relaxation and gradual stress removal accompanied by biofeedback on the anxiety of the students. Journal of knowledge and research in Applied Psychology. 2011; 12(3): 4-11. [In Persian]

39. Moore NC. A review of EEG biofeedback treatment of anxiety disorders. ClinElectroencephalogr. 2000; 31(1): 1-6. [DOI:10.1177/155005940003100105]

40. Garrett BL, Silver MP. The use of EMG and alpha biofeedback to relieve test anxiety in college students. In: Wickramasekera I, editor. Biofeedback, Behavior Therapy, and Hypnosis. Chicago: Nelson-Hall; 1976. 
Journal of Clinical and Basic Research (JCBR). 2019; 3(2): P 1-7.

41. Monastra VJ, Monastra DM, George S. The Effects of Stimulant Therapy, EEG Biofeedback, and Parenting Style on the Primary Symptoms of Attention deficit/hyperactivity Disorder.

ApplPsychophysiol Biofeedback. 2002; 27(4): 231-49. [DOI:10.1023/A:1021018700609]

42. Nosratabadi M. QEEG assessment guided in diagnosis and neurofeedback in treatment of ADHD, An experimental research [MA Thesis in Persian]. Tehran: AllameTatabatabei University; 2008.

43. DehghaniArani F, Rostami R. Effectivness of Neurofeedback training on opium craving. Journal of Daneshvar (Raftar) 2010; 40: 75-84. [In Persian]. 